\title{
Medical termination of a partial hydatidiform mole with coexisting fetus during second trimester; management dilemma: a case report
}

\author{
Jharna Behura ${ }^{1 *}$, Mohini Paul', Ankit Seth ${ }^{2}$, Aafreen Naaz ${ }^{1}$ \\ ${ }^{1}$ Department of Obstetrics and Gynaecology, ${ }^{2}$ Department of Pathology, Kasturba Hospital, Delhi, India
}

Received: 23 September 2020

Accepted: 31 October 2020

*Correspondence:

Dr. Jharna Behura,

E-mail: jharnabehura@yahoo.co.in

Copyright: ( ) the author(s), publisher and licensee Medip Academy. This is an open-access article distributed under the terms of the Creative Commons Attribution Non-Commercial License, which permits unrestricted non-commercial use, distribution, and reproduction in any medium, provided the original work is properly cited.

\begin{abstract}
Partial hydatidiform mole and coexisting foetus is a rare condition, with an incidence of $122,000-1,000,000$ pregnancies. It presents a dilemma for obstetricians when detected in second trimester of pregnancy. Medical termination is effective during second trimester; however, it increases the risk of occurrence of persistent trophoblastic disease. Following a review of literature, it was seen that most of the PHMCF terminated by medical induction during second trimester resulted in the development of PTD and lung metastasis. However, cases terminated by caesarean section during the third trimester did not develop PTD or metastasis. A 34 year old woman, gravida 3 para 2 at 25 weeks and 3 days of gestation, presented with absent fetal movements. She was markedly pale. She had no prior antenatal visits. Ultrasound examination revealed a single intrauterine foetus at 23 weeks of gestation with no cardiac activity. Spalding sign was positive. Liquor was reduced and showed internal echoes, secondary to intramniotic bleed. Placenta was grossly enlarged, anterior in location with multiple cystic areas suggestive of a partial mole. As her haemoglobin was 5.6 grams, she was transfused with 3 units of packed cells. The patient underwent induced medical abortion after counselling for risk of persistent trophoblastic disease and long term follow up. She was followed up with weekly serial serum beta hCG monitoring, which returned to normal within a month. She showed no signs of persistent trophoblastic disease at 3 months follow up and has been advised to continue follow up for a year. Mid-trimester termination of pregnancy due to PHMCF is challenging due to high risk of PTD and metastasis associated with it. Performance of caesarean section is not recommended during second trimester of pregnancy but is a relatively safer strategy to avoid the risks of persistent trophoblastic disease.
\end{abstract}

Keywords: Partial molar pregnancy and coexisting foetus, Second trimester, Persistent trophoblastic disease

\section{INTRODUCTION}

Gestational trophoblastic diseases (GTD) comprises of a broad spectrum of conditions ranging from molar pregnancy, partial mole, persistent trophoblastic disease and choriocarcinoma, all of which arise from impaired fertilization. ${ }^{1,2}$ Molar pregnancies have been subdivided into complete and partial hydatidiform mole on the basis of genetic abnormalities and characteristic histopathological features. ${ }^{3}$ Partial molar pregnancy with a coexisting foetus is a very rare entity and has an incidence of $0.005-0.01 \%$ of all pregnancies. ${ }^{1}$ It usually occurs from dispermic fertilisation of a haploid normal oocyte and produces a triploid set of chromosomes (69 $\mathrm{XXX}, 69 \mathrm{XXY}, 69 \mathrm{XYY}$ ) and is most commonly associated with the presence of a foetus which is malformed. ${ }^{1,2}$ Chorionic gonadotrophin (hCG) levels are generally lower in partial mole than in complete molar pregnancy. ${ }^{2,3} \mathrm{~A}$ diagnosis is made with ultrasonography and measurement of serum beta hCG, usually in first trimester where they are efficiently managed by dilatation and evacuation. In less than $0.005 \%$ of cases, pregnancy 
with a partial mole and a coexisting foetus is present. The management of such pregnancies creates a dilemma particularly when partial hydatidiform mole and coexisting foetus (PHMCF) is diagnosed in second trimester. Persistent or metastatic trophoblastic disease following a partial mole is rare; with an estimated risk of $1.5-6 \% .^{4}$ The risk increases with, a partial mole with a foetus (PMCF) particularly if detected in second trimester. Medical termination of a partial mole with coexisting foetus in second trimester is an effective method; however it significantly increases the risk of persistent trophoblastic disease. ${ }^{5}$

\section{CASE REPORT}

A 34 year old woman, gravida 3 para 2 at 25 weeks and 3 days of gestation, according to her last menstrual period (LMP) was admitted to the labour ward with absent fetal movements since a few days. She was an unbooked case and did not have any prior antenatal visits. Her obstetric history revealed two alive and healthy full term vaginal deliveries. The present pregnancy was a spontaneous conception and there was no history of bleeding pervaginum in the first or second trimester. Her past medical and surgical history was unremarkable.

On general examination, there was marked pallor, pulse rate $90 / \mathrm{min}, \mathrm{BP} 110 / 70 \mathrm{mmHg}$, respiratory rate $20 / \mathrm{min}$, no icterus, cyanosis or pedal oedema was seen. Her chest was clear and heart sounds were normal. On abdominal examination, fundal height was found to correspond to 32 weeks of gestation, though her gestation age was 25 weeks. Uterus was mildly irritable but not tense or tender. Presenting part of the foetus was not made out and no fetal heart could be auscultated.

Her obstetric ultrasound was done, which revealed a single intrauterine foetus at 23 weeks of gestation with no cardiac activity. Spalding sign was positive. Liquor was reduced and showed internal echoes, secondary to intramniotic bleed. Placenta was grossly enlarged, anterior in location with multiple cystic areas suggestive of a partial mole. Bilateral adnexa were normal.

Laboratory workup findings were haemogram; 5.6 gms/dl, platelet count 1.5 lakhs/L, urine analysis was normal. Peripheral smear revealed a microcytic hypochromic picture. Her blood group was B, Rh negative. Her biochemical investigation including LFT and KFT was normal. Thyroid profile and Coagulation profiles were normal. Her chest X-ray was normal and serum beta human chorionic gonadotropin ( $\beta \mathrm{hCG}$ ) was $79,000 \mathrm{mIU} / \mathrm{ml}$.

She was transfused with 3 units of packed red cells and managed conservatively to build up her haemoglobin. When her $\mathrm{Hb}$ was 8 grams, medical termination of pregnancy was planned and the patient was counselled regarding the complications to the mother including excessive vaginal bleeding and the possibility of persistent trophoblastic disease for which she needed to be under long term follow up. She consented for medical termination.

Her pelvic examination revealed cervix to be soft, uneffaced with external OS closed. Tab misoprostol was given vaginally $100 \mu \mathrm{gm} 6$ hourly. A maximum of 4 doses were advised. She expelled both the foetus and placenta after 3 doses of misoprostol. There was no PPH. She was administered anti-D immunoglobulin. Serum $\beta$ hCG decreased consistently in her weekly follow up and became negative after 3 weeks. No evidence of persistent trophoblastic disease has been found at 3 months of follow up.

Macrosopic evaluation of the placenta showed a $9 \times 8 \times 3.5$ $\mathrm{cm}$ discoid placenta with a weight of 320 grams. The presences of focal grape like vesicles were observed on the maternal surface of the placenta, (Figure 1 and Figure 2).

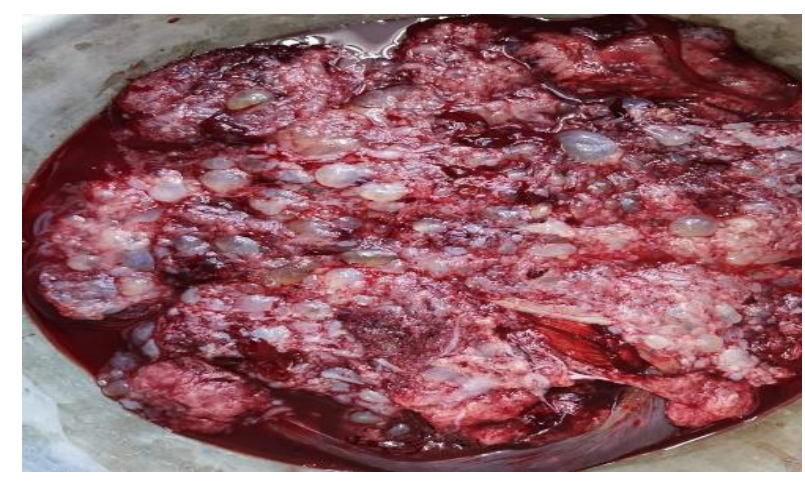

Figure 1: Placenta with focal grape like vesicles.

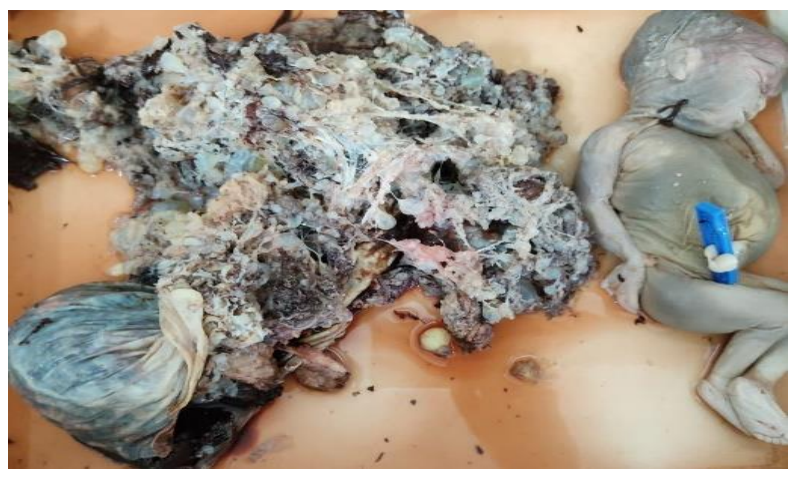

Figure 2: Photomicrograph of gross specimen of partial hydatidiform mole with foetus.

Histopathological examination of placental specimen showed heterogeneity of villi comprising two discrete populations, larger hydropic and smaller fibrotic villi. Larger villi were irregularly shaped with scalloped borders and cistern formation along with minimal trophoblastic proliferation, while smaller ones were normal appearing, lined by syncytiotrophoblastic cells forming syncytial knots at places. Microsections from membranes and cords were unremarkable. Morphological 
findings were consistent with partial hydatidiform mole (Figure 3).

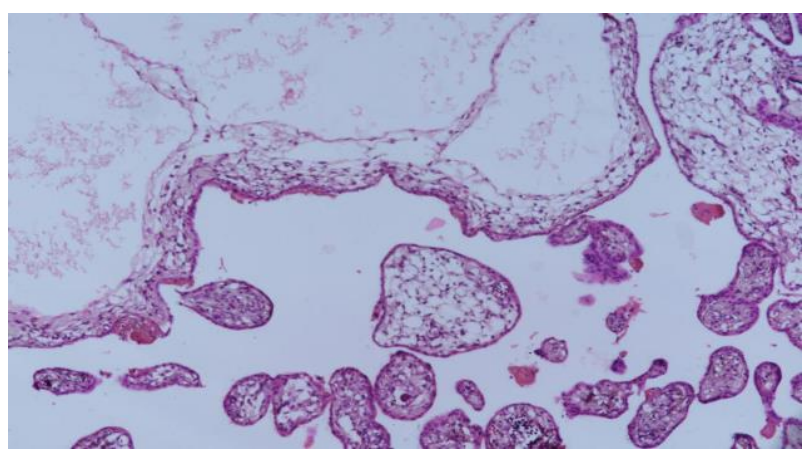

Figure 3: Histopathological picture of partial hydatidiform mole showing normal villi interspersed with large hydropic irregularly shaped villi having scalloped borders and cistern formation (H\&E, 100X).

\section{DISCUSSION}

A partial hydatidiform mole with a coexisting foetus mostly presents with complications such as vaginal bleeding, fetal death, early onset-preeclampsia, hyperthyroidism and risk of gestational trophoblastic neoplasia. To successfully treat this disease, it is empirical to have an early diagnosis. Although the diagnosis of PHMCF is mainly by ultrasonographic examination during the first trimester of pregnancy, a misdiagnosis is not uncommon due to the reassuring presence of a fetal heartbeat and the misinterpretation of abnormal placental echoes as those associated with haematomas. ${ }^{6}$

Following an extensive search of medical literature, since the year 2000, we found 11 PHMCF cases which have been reported previously (Table1). Two of these cases of PHMCF were treated by termination of pregnancy in first trimester with dilatation and suction curettage, resulting in persistent trophoblastic disease with no metastasis in one case. ${ }^{7,8}$ In 4 out of 6 cases $(66.6 \%)$ that were terminated during second trimester, three were medically induced and one by unspecified method, the patients subsequently developed persistent trophoblastic disease and lung metastasis. ${ }^{9-13}$ Four cases that were terminated by Caesarean section, one in second trimester and three in the third trimester did not develop PTD or metastasis, with delivery of live infants. ${ }^{14-19}$ Present case, the PHMCF was terminated by medical method at 25 weeks, using misoprostol and the patient did not develop PTD after three months of follow up. The foetus was dead and $\mathrm{hCG}$ values were on a lower side $(79,000 \mathrm{mIU} / \mathrm{ml})$.

Advances in transvaginal ultrasound and MRI may help in the diagnosis of HMCF in the first trimester; however, HMCF is most often diagnosed at 15-20 weeks of gestation or later. ${ }^{7,12,13}$

The empirical management of these pregnancies in second trimester is difficult. Dilatation and evacuation is the treatment used for molar pregnancies but presence of fetal structures precludes the use of this method. ${ }^{5}$ Medical induction of labour is a safe and effective method for termination of normal pregnancy in second trimester. However, medical termination of a molar pregnancy with a foetus is associated with an increased risk of persistent trophoblastic disease, subsequently requiring chemotherapy, due to the development of increased intrauterine pressure and incomplete evacuation. ${ }^{5}$ Performance of a hysterotomy or a caesarean section is not recommended during second trimester of pregnancy. It may however be a relatively safe strategy to prevent persistent trophoblastic disease.

Table 1: Previously reported cases of partial hydatidiform mole and coexisting foetus in literature.

\begin{tabular}{|llll|lll|}
\hline Author & $\begin{array}{l}\text { Gestational age } \\
\text { at delivery or } \\
\text { abortion, weeks }\end{array}$ & $\begin{array}{l}\text { Method of } \\
\text { termination }\end{array}$ & $\begin{array}{l}\text { Live } \\
\text { neonate }\end{array}$ & PTD & Metastasis & Reference \\
\hline Ingec et al & 10 & D \& E & No & Yes & No & 8 \\
\hline Tay & 11 & D \& E & No & No & No & 7 \\
\hline Kim et al & 14 & Medical & No & yes & Yes* & 9 \\
\hline Zhou et al & 16 & Medical & No & yes & Yes* $^{*}$ & 10 \\
\hline Wang et al & 17 & Medical & No & yes & Yes* $^{*}$ & 19 \\
\hline Shiina et al & 20 & Unknown & No & yes & Yes* & 11 \\
\hline Sanchez-Ferrer et al & 21 & Spontaneous abortion & No & No & No & 14 \\
\hline Chu et al & 24 & Caesarean section & yes & No & No & 15 \\
\hline Copel and Stanek & 28 & Caesarean section & yes & No & No & 16 \\
\hline Navarro Amezcua et al & 29 & Caesarean section & No & No & No & 17 \\
\hline Sun et al & 35 & Caesarean section & Yes & No & No \\
\hline Present case & 25 & Medical & No & No & No \\
\hline
\end{tabular}

*Metastasis located in the lung, PTD; persistent trophoblastic disease; D\&E; dilatation and evacuation. 


\section{CONCLUSION}

Mid-trimester termination of pregnancy due to PHMCF is challenging, both for patients and physicians because of the rarity of the condition and minimal relevant data available. It is difficult to formulate plans and make predictions for treatment and outcomes of patients presenting with PHMCF during the second trimester. It is extremely important to counsel the patients regarding persistent trophoblastic disease, if medical termination is opted.

\section{Funding: No funding sources \\ Conflict of interest: None declared \\ Ethical approval: Not required}

\section{REFERENCES}

1. Smith HO, Kohorn E, Cole LA. Choriocarcinoma and gestational trophoblastic disease. Obstet Gynecol Clin North Am. 2005;32(4):661-84.

2. Soper JT. Gestational trophoblastic disease. Obstet Gynecol. 2006;108(1):176-87.

3. Stevens FT, Katzorke N, Tempfer C, Kreimer U, Bizjak GI, Fleisch MC, et al. Gestational trophoblastic disorders: an update in 2015. Geburtshilfe Frauenheilkd. 2015;75(10):1043-50.

4. Worley MJ, Joseph NT, Berkowitz RS and Goldstein DP. Women with a partial mole during their first pregnancy and diagnosed earlier in gestation are at increased risk of developing gestational trophoblastic neoplasia. Int J Gynecol Canc. 2014;24:941-5.

5. Tidy JA, Gillespie AM, Bright N, Radstone CR, Coleman RE, Hancock BW. Gestational trophoblastic disease: A study of mode of evacuation and subsequent need for treatment with chemotherapy. Gynecol Oncol. 2000;78:309-12.

6. Albers E, Daneshmand S, Hull A. Placental pathology casebook. Complete hydatidiform mole with coexistent term twin pregnancy. J Perinatol. 2001;21:72-5.

7. Tay ET. Partial hydatidiform mole and coexisting viable twin pregnancy. Pediatr Emerg Care. 2013;29: 1298-300.

8. Ingec M, Borekci B, Altas S, Kadanali S: Twin pregnancy with partial hydatidiform mole and coexistent normal fetus. J Obstet Gynaecol. 2006;26:379-80.

9. Kim $\mathrm{CH}$, Kim YH, Kim JW, Kim KM, Cho MK, Kim SM, et al. Triplet pregnancy with partial hydatidiform mole coexisting with two fetuses: A case report. J Obstet Gynaecol Res. 2008;34:641-4.
10. Zhou X, Chen Y, Li Y, Duan Z. Partial hydatidiform mole progression progression into invasive mole with lung metastasis following in vitro fertilization. Oncol Lett. 2012;3:659-61.

11. Shiina H, Oka K, Okane M, Tanno W, Kawasaki T, Nakayama M, et al. Coexisting true hermaphroditism and partial hydatidiform mole developing metastatic gestational trophoblastic tumors, a case report. Virchows Arch. 2002;441:514-8.

12. Herek D, Karabulut N. The role of magnetic resonance imaging in the diagnosis of complete hydatidiform mole in a twin pregnancy. Int $\mathbf{J}$ Gynaecol Obstet. 2013;123:77.

13. Matsui H, Sekiya S, Hando T, Wake N, Tomoda Y. Hyda- tidiform mole coexistent with a twin live fetus: A national collaborative study in Japan. Hum Reprod. 2000;15:608-11.

14. Sánchez-Ferrer ML, Ferri B, Almansa MT, Carbonel P, López-Expósito I, Minguela A, et al. Partial mole with a diploid fetus: case study and literature review. Fetal Diagn Ther. 2009;25(3):354-8.

15. Chu W, Chapman J, Persons DL and Fan F. Twin pregnancy with partial hydatidiform mole and coexistent fetus. Arch Pathol Lab Med. 2004;128: 1305-6.

16. Copeland JW and Stanek J. Dizygotic twin pregnancy with a normal fetus and a nodular embryo associated with a partial hydatidiform mole. Pediatr Dev Pathol. 2010;13:476-80.

17. Navarro AME, Castellanos RJ, Cardona GO, Torres GLG. Twin pregnancywith partial hydatidiform mole and alive fetus: Case report. Ginecol Obstet Mex. 2008;76:275-9.

18. Sun CJ, Zhao YP, Yu S, Fan L, Wu QQ, Li GH, et al. Twin pregnancy and partial hydatidiform mole following in vitro fertilization and embryos transfer: A novel case of placental mosaicism. Chin Med J. 2012;125:4517-9.

19. Yinfeng W, Honglang Q, Jinhua W. Medical termination of a partial hydatidiform mole and coexisting fetus during the second trimester : A case report. Oncol Lett. 2015;10:3625-8.

Cite this article as: Behura J, Paul M, Seth A, Naaz A. Medical termination of a partial hydatidiform mole with coexisting fetus during second trimester; management dilemma: a case report. Int J Reprod Contracept Obstet Gynecol 2020;9:5172-5. 